\title{
Investigation on Furan Levels in Pressure-Cooked Foods
}

\author{
Adriana P. Arisseto, Eduardo Vicente, and Maria Cecília F. Toledo \\ Food Science and Quality Center, Institute of Food Technology, Avenida Brasil 2880, CP 139, 13070-178 Campinas, SP, Brazil \\ Correspondence should be addressed to Adriana P. Arisseto; adriana.arisseto@gmail.com
}

Received 29 November 2012; Revised 20 December 2012; Accepted 29 December 2012

Academic Editor: Thierry Thomas-Danguin

Copyright (c) 2013 Adriana P. Arisseto et al. This is an open access article distributed under the Creative Commons Attribution License, which permits unrestricted use, distribution, and reproduction in any medium, provided the original work is properly cited.

\begin{abstract}
Furan is a food processing contaminant classified as possibly carcinogenic to humans. As the occurrence of furan has been reported in a variety of foods processed in sealed containers, the objective of this work was to investigate if the contaminant can be found in home-cooked foods prepared in a pressure cooker. For that, several foods including beans, soy beans, whole rice, beef, pork, potato, and cassava were pressure-cooked and analyzed for the furan content by gas chromatography coupled to mass spectrometry preceded by a headspace solid phase microextraction (HS-SPME-GC/MS). Furan was not found above the limit of quantification in the pressure-cooked samples. No furan has either been found in reheated samples after 24 hours under cold storage. Although levels up to $173 \mu \mathrm{g} / \mathrm{kg}$ were already reported for commercial canned/jarred foods, it seems that the cooking in a pressure cooker may not represent a concern in relation to the occurrence of furan in foods.
\end{abstract}

\section{Introduction}

Furan $\left(\mathrm{C}_{4} \mathrm{H}_{4} \mathrm{O}\right)$ is a colorless flammable liquid with an ethereal odor, having a low molecular weight of 68 and a high volatility with the boiling point of $31^{\circ} \mathrm{C}$ [1]. Furan is classified as a possible human carcinogen (group 2B) by the International Agency for Research on Cancer in view of its hepatotoxicity, cytotoxicity, and carcinogenicity verified in experimental animals [2].

In 2004, American researchers demonstrated that furan can be formed during the thermal treatment of several foods, including canned/jarred products [3]. According to this study, levels up to 112 and $173 \mu \mathrm{g} / \mathrm{kg}$ were found in jarred baby food and canned gravies, respectively. The occurrence of furan in canned and jarred foods has been attributed to the thermal treatment carried out in hermetically sealed containers which avoids losses of the contaminant by volatilization and permits its accumulation in the products [4].

In order to evaluate the processing parameters and mechanisms that lead to the furan formation in canned/jarred foods, pressure cooking conditions (in general $120^{\circ} \mathrm{C}$ for $20 \mathrm{~min}$ ) have been used to simulate the sterilization step employed in a typical commercial canning operation in which the generation of the contaminant is supposed to occur [4-10]. These studies have confirmed that furan can be formed when model systems and retail foods are heated in sealed vials under the mentioned conditions.

However, it should be emphasized that the pressure cooking is a common and widely used domestic practice which permits food to be cooked faster, as the pressure built up inside the cooker allows the liquid in the pot to rise to a temperature higher than $100^{\circ} \mathrm{C}$. Considering that the furan formation under pressure cooking conditions has already been demonstrated in model systems and retail foods heated in sealed vials, it is important to evaluate if the contaminant can be found in home pressure-cooked foods. Moreover, the influence on furan levels of other practices commonly applied after the pressure cooking, such as an additional cooking without the lid and reheating after cold storage, was also investigated.

\section{Materials and Methods}

2.1. Standards and Chemicals. Furan and $\left[{ }^{2} \mathrm{H}_{4}\right]$ furan (furan$\mathrm{d}_{4}$ ) were obtained from Sigma-Aldrich (Sigma-Aldrich Corp., St. Louis, MO, USA) at purity higher than $98 \%$. Methanol was of HPLC-grade (Tedia Company Inc., Fairfield, OH, USA) and water was purified by reverse osmosis (Gehaka, São Paulo, SP, Brazil). Individual stock solutions of 
both standards at ca $2 \mathrm{mg} / \mathrm{mL}$ were prepared by dissolving in methanol. Intermediate and work solutions at $c a 20 \mu \mathrm{g} / \mathrm{mL}$ and $0.2 \mu \mathrm{g} / \mathrm{mL}$, respectively, were prepared in water.

2.2. Samples. Several foods were considered in the present study, including beans, soy beans, whole rice, beef, pork, potato, and cassava. The samples were obtained from the local market. With exception of beans, soy beans, and whole rice, the samples were cut in cubs of approximately $2 \times 2 \mathrm{~cm}$ prior to cooking. Potato and cassava were previously peeled.

2.3. Pressure Cooking. A domestic aluminium pressure cooker of 4.5 litres (Clock, Panex LTDA, São Bernardo do Campo, SP, Brazil) was used in the experiments. After the addition of $400 \mathrm{~g}$ of the fresh sample (prepared as mentioned above) and $1.5 \mathrm{~L}$ of water at room temperature, the cooker was immediately closed and the cooking was performed during $20 \mathrm{~min}$ after the first release of steam from the pressure valve. The samples were cooked and reheated directly in the water in order to reproduce the domestic preparation of soups and stews.

Before opening, the pressure cooker was cooled under tap water for sufficient time to eliminate the pressure. Then, a portion of the cooked sample was collected as quickly as possible and properly stored until homogenization and analysis. The remained sample was subdivided in another two portions. The first one was kept in the pressure cooker and was cooked for additional $10 \mathrm{~min}$ without the lid. The second portion was stored under refrigeration during 24 hours and reheated in an open saucepan during $5 \mathrm{~min}$ after boiling. All samples were stored at $4^{\circ} \mathrm{C}$ for at least 4 hours before homogenization in order to avoid furan loss by volatilization.

2.4. Determination of Furan. The furan content was determined in the fresh, cooked, refrigerated, and reheated samples by using an in-house validated method based on gas chromatography coupled to mass spectrometry preceded by headspace solid phase microextraction (HS-SPME-GC/MS) according to Arisseto et al. [11]. Briefly, a portion of $1 \mathrm{~g}$ of homogeneous sample was weighed in a chilled $40 \mathrm{~mL}$ screw-cap glass vial fitted with silicone-PTFE septum containing a $15 \mathrm{~mm} \times 5 \mathrm{~mm}$ PTFE-coated stir bar. Aliquots of $125 \mu \mathrm{L}$ of furan- $\mathrm{d}_{4}$ working standard solution $0.2 \mu \mathrm{g} / \mathrm{mL}$ and $875 \mu \mathrm{L}$ of water were added and the vial was immediately closed. The SPME was carried out in a $75 \mu \mathrm{m}$ carboxenpolydimethylsiloxane (CAR-PDMS) fiber (Supelco, Bellefonte, PA, USA) at $25^{\circ} \mathrm{C}$ during $30 \mathrm{~min}$, under a constant magnetic agitation rate of $1200 \mathrm{rpm}$, approximately. All samples were analysed in duplicate.

2.5. GC/MS Analysis. The analyses were performed on an HP 6890 gas chromatography equipped with an MSD 5973 mass spectrometer (Agilent Technologies, Palo Alto, CA, USA). Helium was used as the carrier gas at a constant flow rate of $0.7 \mathrm{~mL} / \mathrm{min}$. The Programmable Temperature Vaporizing (PTV) injector was operated in the splitless mode under the following temperature program: $40^{\circ} \mathrm{C}$ (held for $0.1 \mathrm{~min}$ ), $700^{\circ} \mathrm{C} / \mathrm{min}$ up to $230^{\circ} \mathrm{C}$ (held for $23 \mathrm{~min}$ ). The split valve remained open for $0.7 \mathrm{~min}$. The separation was performed on a $60 \mathrm{~m} \times 0.25 \mathrm{~mm}, d_{f} 0.25 \mu \mathrm{m}$ HP-INNOWAX capillary column (Agilent Technologies) and the oven temperature program was $30^{\circ} \mathrm{C}$ (held for $0.1 \mathrm{~min}$ ), $2^{\circ} \mathrm{C} / \mathrm{min}$ up to $40^{\circ} \mathrm{C}$ (held for $3 \mathrm{~min}$ ), and $12^{\circ} \mathrm{C} / \mathrm{min}$ up to $200^{\circ} \mathrm{C}$ (held for $2 \mathrm{~min}$ ). The mass spectrometer was operated in a positive electron impact ionization mode $(+\mathrm{EI})$ with $70 \mathrm{eV}$ of the electron energy. The quadrupole and the ionization source were maintained at 150 and $230^{\circ} \mathrm{C}$, respectively. The selected ion monitoring (SIM) was used for the detection of furan and furan- $\mathrm{d}_{4}$, using $m / z 68^{*} / 39 / 69$ for furan and $m / z 72 * / 42$ for furan- $\mathrm{d}_{4}$ ( ${ }^{*}$ quantifier ions). A dwell time of $100 \mathrm{~ms}$ was used for all the ions.

2.6. Identification and Quantification. The relative retention time (RRT) and the presence of characteristic ions were considered for identification of furan in the samples. For confirmatory purposes, an acceptable deviation of $\pm 0.5 \%$ for RRT, $\pm 10 \%$ for ionic relative abundance considering $\mathrm{m} / z$ $39 / 68$, and $\pm 50 \%$ for ionic relative abundance considering $m / z 69 / 68$ were used by comparing the sample with a standard solution [12]. The quantification of furan was carried out by extrapolation from a linear analytical curve, using the quantifier ions $m / z 68$ (furan) and $m / z 72$ (furan- $\mathrm{d}_{4}$, internal standard).

\section{Results and Discussion}

Although several studies have been published on furan levels in commercial products, few data is available for homecooked foods. Fromberg et al. [13] evaluated the formation of furan during domestic cooking such as grilling, roasting, baking, frying, and cooking in saucepan and microwave. However, the presence of furan in home-cooked foods prepared in a pressure cooker has not been investigated so far.

Figure 1 illustrates a typical ion chromatogram of a pressure-cooked pork sample and the levels of furan obtained for the pressure-cooked foods selected in the present study are shown in Table 1. As expected, furan was not detected in the fresh samples. The results also indicate that the pressure cooking did not produce quantifiable levels of the contaminant for any of the evaluated samples.

Several furan derivatives were already identified in pressure-cooked meats. In a study on volatile constituents of pressure-cooked pork liver isolated by simultaneous steam distillation and continuous solvent extraction, Mussinan and Walradt [14] identified 23 furanic compounds. Other authors found out 3 furan derivatives between the most potent aromatic constituents of pressure-cooked hen meat [15]. However, the presence of the unsubstituted compound has not been reported in these studies, which is consistent with the results obtained in the present work.

Nevertheless, taking into account that the formation of furan has already been demonstrated in model systems and retail foods heated in sealed vials under pressure cooking conditions, it could be suggested that any furan possibly 


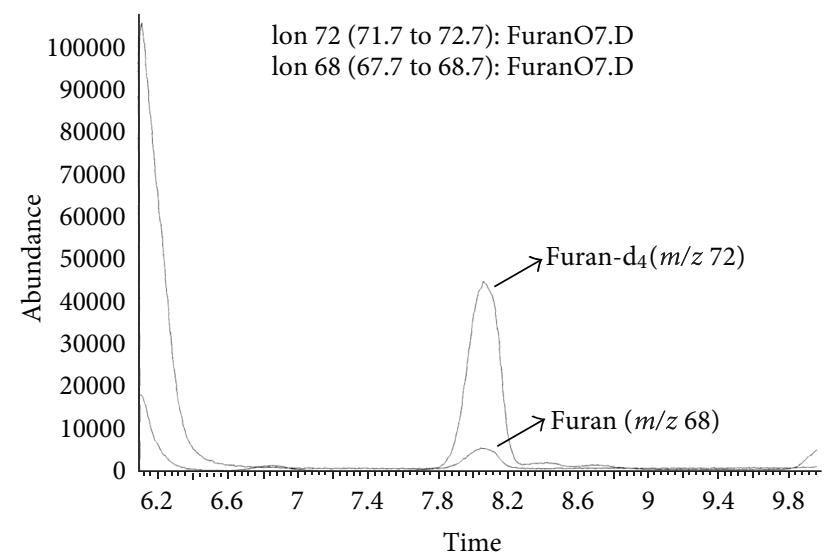

FIGURE 1: Ion chromatogram of a sample of cooked pork containing $<2.4 \mu \mathrm{g} / \mathrm{kg}(\mathrm{m} / z 68$ and 72: quantifier ions; carrier gas: helium; flow rate: $0.7 \mathrm{~mL} / \mathrm{min}$; Programmable Temperature Vaporizing (PTV) injector: $40^{\circ} \mathrm{C}$ (held for $0.1 \mathrm{~min}$ ), $700^{\circ} \mathrm{C} / \mathrm{min}$ up to $230^{\circ} \mathrm{C}$ (held for $23 \mathrm{~min}$ ); mode: splitless; column: $60 \mathrm{~m} \times 0.25 \mathrm{~mm}, d_{f} 0.25 \mu \mathrm{m}$ HP-INNOWAX; oven: $30^{\circ} \mathrm{C}$ (held for $0.1 \mathrm{~min}$ ), $2^{\circ} \mathrm{C} / \mathrm{min}$ up to $40^{\circ} \mathrm{C}$ (held for $3 \mathrm{~min}$ ), $12^{\circ} \mathrm{C} / \mathrm{min}$ up to $200^{\circ} \mathrm{C}$ (held for $2 \mathrm{~min}$ ); mass spectrometer: positive electron impact ionization $(70 \mathrm{eV})$; quadrupole temperature: $150^{\circ} \mathrm{C}$; ionization source temperature: $230^{\circ} \mathrm{C}$; dwell time: $100 \mathrm{~ms}$ ).

TABLE 1: Furan levels in pressure-cooked foods.

\begin{tabular}{lcc}
\hline Food & \multicolumn{2}{c}{ Furan $(\mu \mathrm{g} / \mathrm{kg})$} \\
& Raw & Cooked \\
\hline Beans & nd & $<2.4$ \\
Whole rice & nd & $<2.4$ \\
Soy beans & nd & $<2.4$ \\
Beef & nd & nd \\
Pork & nd & $<2.4$ \\
Potato & nd & nd \\
Cassava & nd & nd \\
\hline
\end{tabular}

$\mathrm{nd}=$ values below the limit of detection ( $\mathrm{LOD}=0.7 \mu \mathrm{g} / \mathrm{kg})$.

formed in the studied samples was lost with the steam that is released by the valve when a determined pressure is reached. This is in accordance with the observations reported by Hasnip et al. [4] that dried vegetables heated in open vials accumulated very little furan in comparison with sealed samples.

It should be noted that the possible release of furan to the air kitchen during the pressure cooking could contribute for an occupational exposure to the contaminant. This should be further investigated since it has already been demonstrated that furan was found in the air kitchen as a result of some procedures, such as the addition of water to a cafetiere, the frying of chipped potatoes in an open chip pan, and baking some foods in an oven [16].

Figure 2 illustrates the levels of furan obtained in the subsequent cooking experiments. It can be seen that no furan has also been found in quantifiable amounts in the samples cooked for additional $10 \mathrm{~min}$ without the lid as well as in the reheated samples after 24 hours under cold storage.



Figure 2: Furan levels obtained after reheating (for illustration purposes: levels below limit of detection (LOD) were considered as half of LOD $(0.35 \mu \mathrm{g} / \mathrm{kg})$ and levels below limit of quantification (LOQ) were considered as half of LOQ $(1.2 \mu \mathrm{g} / \mathrm{kg})$ ).

Data available in the literature on the furan content after the application of common warming procedures have shown conflicting results. Some authors reported furan losses of $29-85 \%$, whereas others have found that furan persists during normal heating practices $[4,17,18]$. It has also been demonstrated that furan could even be formed at levels up to $29.2 \mu \mathrm{g} / \mathrm{kg}$ during the reheating of baby foods containing potatoes after cold storage [19]. However, no significant furan loss or formation was observed in the samples investigated here.

It was very recently reported that additional amounts of furan can be formed from potential precursors such as 2-butenal and furfural during the thermal desorption of the fiber when using SPME-GC/MS [20]. Although this technique was applied in the present study, it seems that the general impact of the possible artifactual furan formation on the obtained results was negligible.

\section{Conclusions}

Furan has been reported in a variety of thermally processed foods, including canned/jarred commercial products as well as home-cooked foods obtained by grilling, roasting, baking, or frying. Although the conditions of pressure cooking can lead to furan formation in model systems and retail foods heated in sealed vials, as demonstrated by several studies, it seems that this procedure as applied at a domestic level may not represent a concern in relation to the occurrence of furan in home pressure-cooked foods. This is quite important considering that, to date, the research on furan has not been successful in identifying practical and consistently effective solutions for decreasing the levels of the contaminant in foods [21]. Also, as the interventions on furan reported in the scientific literature are mostly targeted at the level of the consumer rather than industrial production methods, the identification of domestic practices that could produce foods with reduced furan levels is highly desirable. 


\section{Conflict of Interests}

The authors declare that they have no conflict of interests.

\section{Acknowledgments}

The scholarship and the financial support were provided by FAPESP (Process 2008/50095-0) and CNPq (Process 474267/2008-3 and Proc. 578381/2008-7).

\section{References}

[1] NTP (National Toxicological Program), “Toxicology and carcinogenesis studies of furan (CAS No. 110-00-9) in F344 rats and B6C3F1 mice (gavage studies)," Technical Report Series 402, US Department of Health and Human Services, 1993, http://ntp.niehs.nih.gov/ntp/htdocs/LT_rpts/tr402.pdf.

[2] IARC (International Agency for Research on Cancer), "Furan," in IARC Monographs on the Evaluation of Carcinogenic Risks of Chemicals to Humans, vol. 63, Lyon, France, 1995.

[3] US FDA (Food and Drug Administration), "Exploratory data on furan in food: individual food products," 2004, http:// www.fda.gov/food/foodsafety/foodcontaminantsadulteration/ chemicalcontaminants/furan/ucm078439.

[4] S. Hasnip, C. Crews, and L. Castle, "Some factors affecting the formation of furan in heated foods," Food Additives and Contaminants, vol. 23, no. 3, pp. 219-227, 2006.

[5] A. Limacher, J. Kerler, B. Conde-Petit, and I. Blank, "Formation of furan and methylfuran from ascorbic acid in model systems and food," Food Additives and Contaminants, vol. 24, no. 1, pp. 122-135, 2007.

[6] A. Limacher, J. Kerler, T. Davidek, F. Schmalzried, and I. Blank, "Formation of furan and methylfuran by Maillard-type reactions in model systems and food," Journal of Agricultural and Food Chemistry, vol. 56, no. 10, pp. 3639-3647, 2008.

[7] A. Owczarek-Fendor, B. De Meulenaer, G. Scholl et al., "Importance of fat oxidation in starch-based emulsions in the generation of the process contaminant furan," Journal of Agricultural and Food Chemistry, vol. 58, no. 17, pp. 9579-9586, 2010.

[8] F. Van Lancker, A. Adams, A. Owczarek-Fendor, B. De Meulenaer, and N. De Kimpe, "Mechanistic insights into furan formation in maillard model systems," Journal of Agricultural and Food Chemistry, vol. 59, no. 1, pp. 229-235, 2011.

[9] A. Owczarek-Fendor, B. De Meulenaer, G. Scholl et al., "Furan formation from lipids in starch-based model systems, as influenced by interactions with antioxidants and proteins," Journal of Agricultural and Food Chemistry, vol. 59, no. 6, pp. 2368-2376, 2011.

[10] A. Owczarek-Fendor, B. De Meulenaer, G. Scholl et al., "Furan formation in starch-based model systems containing carbohydrates in combination with proteins, ascorbic acid and lipids," Food Chemistry, vol. 133, pp. 816-821, 2012.

[11] A. P. Arisseto, E. Vicente, and M. C. de Figueiredo Toledo, "Determination of furan levels in commercial samples of baby food from Brazil and preliminary risk assessment," Food Additives and Contaminants A, vol. 27, no. 8, pp. 1051-1059, 2010.

[12] EC (European Commission), "Commission Decision 2002/657/EC concerning the performance of analytical methods and the interpretation of results," Official Journal of European Communities, vol. 221, pp. 8-36, 2002.
[13] A. Fromberg, S. Fagt, and K. Granby, "Furan in heat processed food products including home cooked food products and ready-to-eat products," External Scientific Report, European Food Safety Authority, 2009, http://www.efsa.europa .eu/en/supporting/doc/1e.pdf.

[14] C. J. Mussinan and J. P. Walradt, "Volatile constituents of pressure cooked pork liver," Journal of Agricultural and Food Chemistry, vol. 22, no. 5, pp. 827-831, 1974.

[15] P. Farkaš, J. Sádecká, M. Kováč, B. Siegmund, E. Leitner, and W. Pfannhauser, "Key odourants of pressure-cooked hen meat," Food Chemistry, vol. 60, no. 4, pp. 617-621, 1997.

[16] C. Crews, "Consumer exposure to furan from heat-processed foods and kitchen air," Scientific/Technical Report, European Food Safety Authority, 2009, http://www.efsa.europa.eu/ en/supporting/doc/30e.pdf.

[17] T. Goldmann, A. Périsset, F. Scanlan, and R. H. Stadler, "Rapid determination of furan in heated foodstuffs by isotope dilution solid phase micro-extraction-gas chromatography-mass spectrometry (SPME-GC-MS)," Analyst, vol. 130, no. 6, pp. 878-883, 2005.

[18] O. Zoller, F. Sager, and H. Reinhard, "Furan in food: headspace method and product survey," Food Additives and Contaminants, vol. 24, no. 1, pp. 91-107, 2007.

[19] D. W. Lachenmeier, H. Reusch, and T. Kuballa, "Risk assessment of furan in commercially jarred baby foods, including insights into its occurrence and formation in freshly homecooked foods for infants and young children," Food Additives and Contaminants A, vol. 26, no. 6, pp. 776-785, 2009.

[20] A. Adams, F. Van Lancker, B. De Meulenaer, A. OwczarekFendor, and N. De Kimpe, "On-fiber furan formation from volatile precursors: a critical example of artifact formation during Solid-Phase Microextraction," Journal of Chromatography B, vol. 897, pp. 37-41, 2012.

[21] CCCF (Codex Committee on Contaminants in Foods), Discussion Paper on Furan, 5th Session, The Hague, The Netherlands, 2011. 

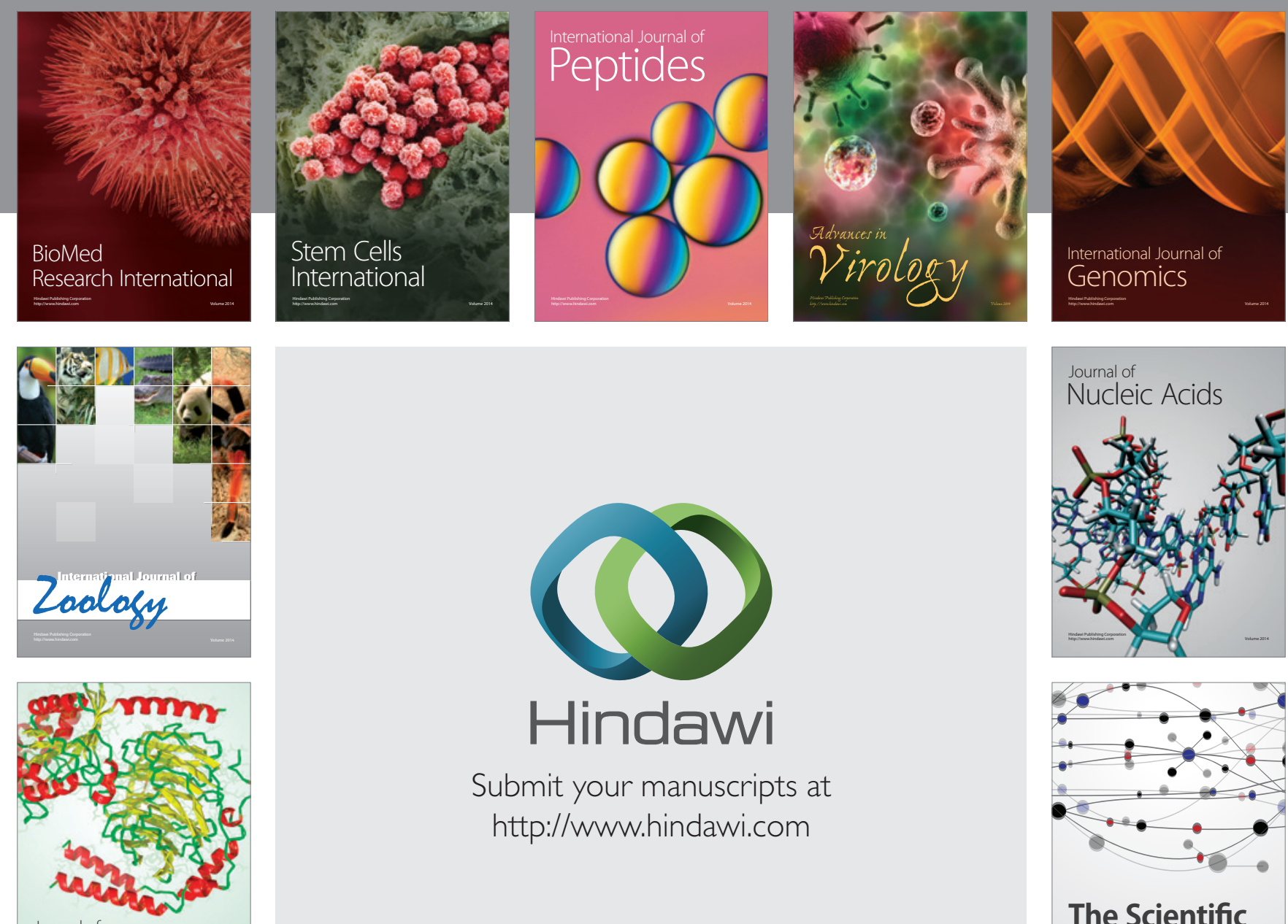

Submit your manuscripts at

http://www.hindawi.com

Journal of
Signal Transduction


The Scientific World Journal
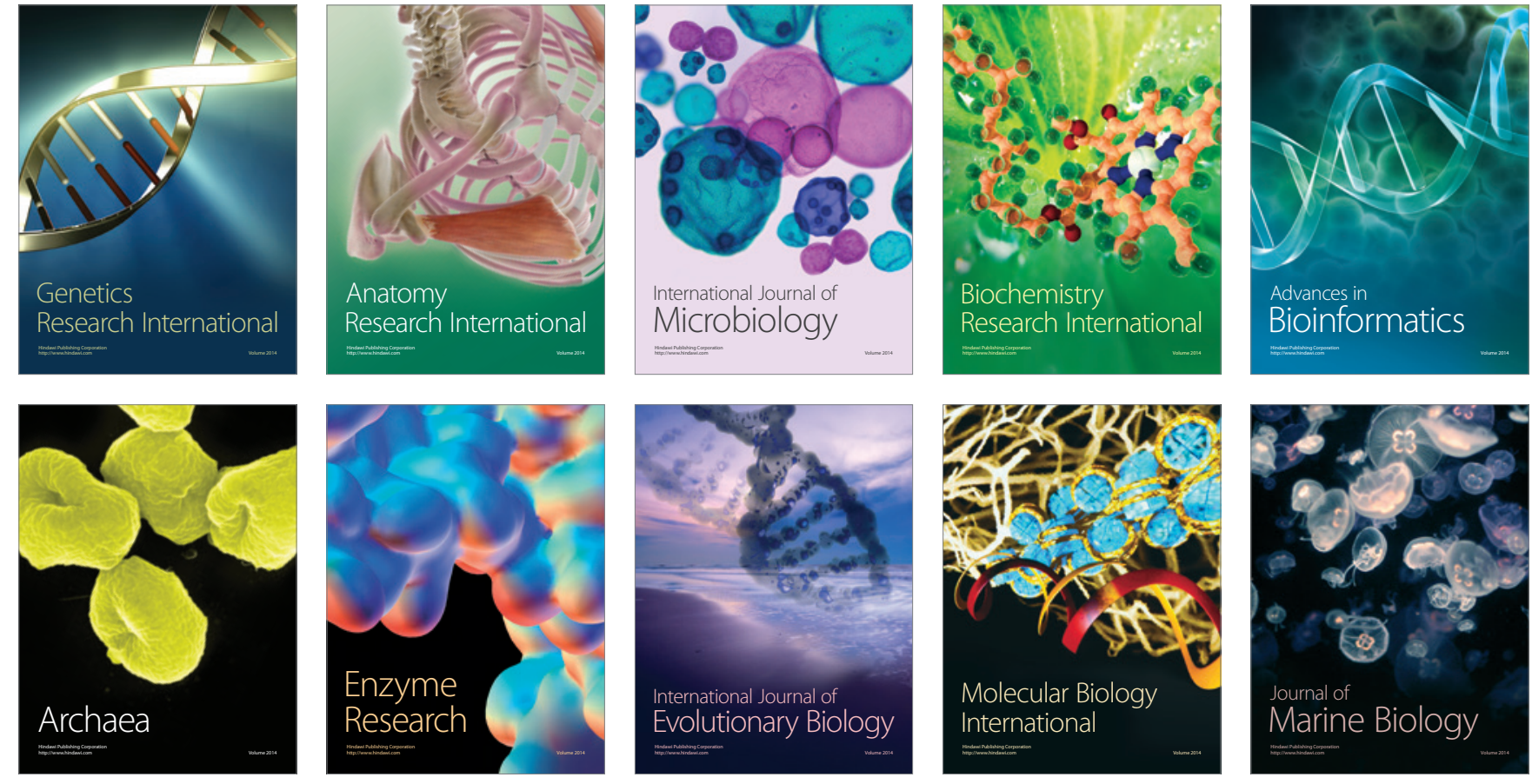